\title{
Sonderzeichen und Abkürzungen
}

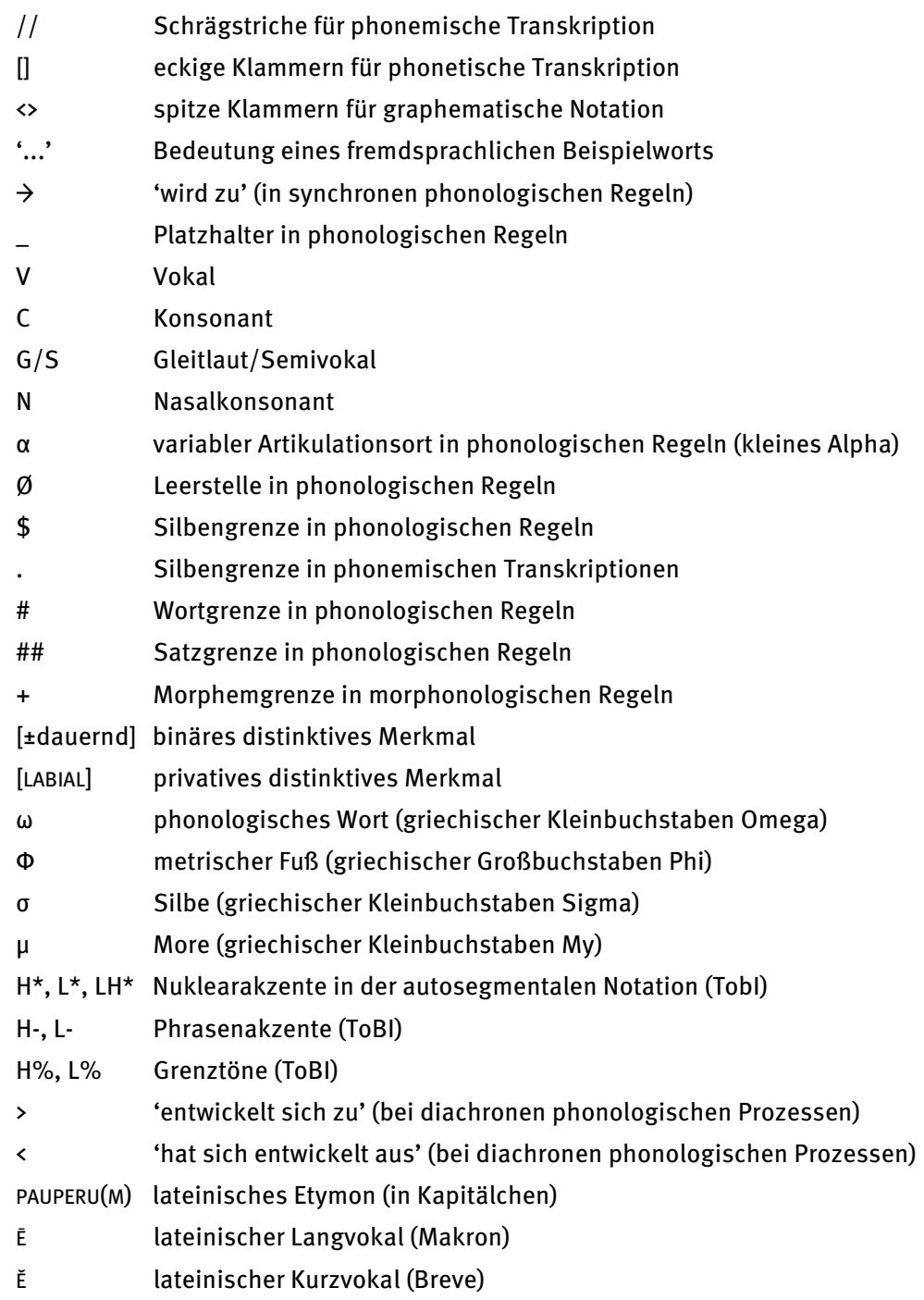

\section{Sprachen und Dialekte}

abr. Abruzzesisch

ahd. Althochdeutsch

dt. Deutsch

engl. Englisch

fr. Französisch

germ. Germanisch 


$\begin{array}{ll}\text { gr. } & \text { Griechisch } \\ \text { it. } & \text { Italienisch } \\ \text { kamp. } & \text { Kampanisch } \\ \text { lat. } & \text { Lateinisch } \\ \text { lig. } & \text { Ligurisch } \\ \text { lomb. } & \text { Lombardisch } \\ \text { mhd. } & \text { Mittelhochdeutsch } \\ \text { molis. } & \text { Molisanisch } \\ \text { neap. } & \text { Neapolitanisch } \\ \text { nhd. } & \text { Neuhochdeutsch } \\ \text { piem. } & \text { Piemontesisch } \\ \text { pt. } & \text { Portugiesisch } \\ \text { sard. } & \text { Sardisch } \\ \text { siz. } & \text { Sizilianisch } \\ \text { sp. } & \text { Spanisch } \\ \text { tosk. } & \text { Toskanisch } \\ \text { ven. } & \text { Venetisch } \\ \text { venez. } & \text { Venezianisch }\end{array}$

\section{Wortarten und grammatische Kategorien}

Art. Artikel

Adj. Adjektiv

Adv. Adverb

f. feminin (Genus)

m. maskulin (Genus)

N / Subst. Nomen / Substantiv

pl. Plural (Numerus)

Präp. Präposition

Pron. Pronomen

sg. $\quad$ Singular (Numerus) 